\title{
Prevalence of Malocclusion and Evaluation of Orthodontic Treatment Need amongst Patients in Pokhora, Nepal
}

\author{
Dr Umesh Parajuli,' Dr Sapna Laxmi Tuladhar,2 Dr Manish Bajracharya,3 Dr Manju Pandey \\ 'Asso Professor, 4Lecturer, Dept of Orthodontics, ${ }^{2}$ Lecturer, Dept of Prosthodontics, \\ College of Dental Surgery, Gandaki Medical College, Pokhara, Nepal \\ ${ }^{3}$ Asso Professor, Dept of Orthodontics, National Academy of Medical Sciences, Kathmandu, Nepal
}

Correspondence: Dr Umesh Parajuli; Email: drumeshparajuli@gmail.com

\section{ABSTRACT}

Introduction: Prevalence of malocclusion and orthodontic treatment need varies according to different region based on ethnic diversity.

Objective: To assess the prevalence of malocclusion and orthodontic treatment need amongst patients visiting College of Dental Surgery, Gandaki Medical College, Pokhara, Nepal.

Materials \& Method: A cross-sectional study based on WHO-Oral Health Survey Basic Methods using Community Periodontal Index (CPI) probe and mouth mirror was conducted. The malocclusion based on Angle's classification, overjet, overbite, open bite, crowding, spacing and cross bites were recorded. Dental Health Components (DHC) of Index of Orthodontic Treatment Need (IOTN) was recorded. The frequency distribution was calculated and chi square test was used to assess the gender difference.

Result: The prevalence of normal occlusion was $5.8 \%$, Angle's Class I malocclusion was $67.9 \%$, Class II was $19.5 \%$ and Class III was $6.8 \%$. Crowding (51.07\%) was more common malocclusion trait than spacing (24.46\%). There were no significant differences in distribution of various occlusal traits between male and female subjects. Orthodontic treatment need based on DHC showed: $19.40 \%$ were in definite/extreme need of treatment (Grade 4/5), 21.93\% had borderline need (Grade 3) and 58.67\% had no/ little need of treatment (Grade 1/2).

Conclusion: Angle's Class I was the most common malocclusion trait (67.9\%) followed by anterior crowding (51.07\%). $19.40 \%$ patients visiting the teaching hospital in Pokhara are in definite or extreme need of orthodontic treatment.

Keywords: Dental Health Component, Index of Orthodontic Treatment Need, malocclusion

\section{INTRODUCTION}

Prevalence of malocclusion and the need of orthodontic treatment are deemed important and included in national health surveys in various countries. ${ }^{1-3}$ The major etiology of malocclusion is attributed to genetic, racial and environmental factors. ${ }^{4}$ Malocclusion has been shown to affect the person psychologically, reducing the self-esteem and resulting in fewer opportunities in life. ${ }^{5}$

Various methods are used to assess orthodontic treatment need; while Index of Orthodontic Treatment Need (IOTN) is most commonly used to assess occlusal traits. ${ }^{6}$

Prevalence of malocclusion and the treatment needs have been established in few regions of Nepal. ${ }^{7-10}$ Few prevalence studies of malocclusion were done in
Western region of Nepal but the need for orthodontic treatment has not been established. ${ }^{11,12}$ Therefore the objective of this study is to assess prevalence of various malocclusion traits and to evaluate the orthodontic treatment need based on DHC of IOTN among the patients visiting Gandaki Medical College, Pokhara.

\section{MATERIALS AND METHOD}

This is a hospital-based cross-sectional study conducted at College of Dental Surgery, Gandaki Medical College, Pokhara over a period of six months from October 2017 to March 2018. Sample size was calculated using the formula $\mathrm{N}=4 \mathrm{pq} / \mathrm{L}^{2}$ (where, $\mathrm{p}=$ prevalence rate $62.28 \%$, 13 $q=1-p, L=$ permissible error in the estimation of ' $P$ ', $L=5 \%$ of $62.28=3.114)$. The sample size was estimated to be 969. The total sample size consisted of 1026 patients of age group 11 to 30 years. Patients undergoing fixed orthodontic treatment, history of extractions, systemic 
health problems and developmental anomalies were excluded from the study. Ethical clearance was obtained from the Institutional Review Committee. Consent was obtained from adult patients and from the parents for adolescent group.

The examination was done by a single examiner on a dental chair with illumination. The parameters were recorded based on WHO- Oral Health Survey Basic Methods using Community Periodontal Index (CPI) probe and mouth mirror. ${ }^{14}$ Malocclusion based on Angle's classification, over jet, over bite, open bite, crowding, spacing and cross bite were recorded in a performa. Dental Health Component (DHC) of IOTN index was recorded for various malocclusion traits. This was classified into three categories of treatment need: Grade 1 and 2 (no or little need of treatment), Grade 3 (borderline need), Grade 4 and 5 (definite or extreme need).

The data were entered in MS Excel and analyzed in SPSS Version 17. The frequency distributions were calculated and chi square test was used to assess the differences in malocclusion traits between male and female subjects; $\mathrm{p}$-value $<0.05$ was considered significant.

\section{RESULT}

Out of 1026 patients screened; 512 (49.9\%) were female and 514 (50.1\%) were male. The mean age was 23.06 +4.7 years

The distribution of occlusal trait was normal occlusion 5.8\%, Angle's Class I malocclusion 67.9\%, Class I| 19.5\% and Class III $6.8 \%$ (Table 1). Excessive overjet was seen in $39.4 \%$, excessive overbite in $46.9 \%$; while only $27.8 \%$ exhibited normal overbite. Open bite was prevalent in $2.8 \%$ of the patients. Crowding was more common than spacing, which were $51.07 \%$ and $24.46 \%$ respectively. Midline diastema was present in 251 (24.46\%) patients. Anterior crossbite was more common than posterior cross bite; which were $10.3 \%$ and $6.8 \%$ respectively. No statistically significant difference was observed in any of the occlusal traits studied among male and female subjects. The IOTN-Dental Health Component showed treatment need as given in Table 2 .

\section{Table 1: Distribution of different occlusal traits}

\begin{tabular}{|c|c|c|c|c|c|}
\hline \multicolumn{2}{|c|}{ Occlusal traits } & Total & Male & Female & $p$-Value \\
\hline \multirow{4}{*}{ Angle's Classification } & Normal Occlusion & $59(5.8 \%)$ & $25(42.4 \%)$ & $34(57.63 \%)$ & \multirow{4}{*}{0.34} \\
\hline & Class I malocclusion & $697(67.9 \%)$ & $361(51.8 \%)$ & $336(48.21 \%)$ & \\
\hline & Class II malocclusion & $200(19.5 \%)$ & $97(48.5 \%)$ & $103(51.5 \%)$ & \\
\hline & Class III malocclusion & $70(6.8 \%)$ & $31(44.3 \%)$ & $39(55.7 \%)$ & \\
\hline \multirow{3}{*}{ Overjet } & Normal (1-2mm) & $485(47.3 \%)$ & $248(51.1 \%)$ & $237(48.86 \%)$ & \multirow{3}{*}{0.81} \\
\hline & Excessive (>2mm) & $404(39.4 \%)$ & 198 (49\%) & $206(51 \%)$ & \\
\hline & Reduced (<1mm) & $137(13.4 \%)$ & $68(49.6 \%)$ & $69(50.4 \%)$ & \\
\hline \multirow{3}{*}{ Overbite } & Normal (25-40\%) & $285(27.8 \%)$ & $132(46.3 \%)$ & $153(53.7 \%)$ & \multirow{3}{*}{0.63} \\
\hline & Excessive (>40\%) & $481(46.9 \%)$ & $257(53.4 \%)$ & $224(46.6 \%)$ & \\
\hline & Reduced (<25\%) & $260(25.3 \%)$ & $125(48.1 \%)$ & $135(51.9 \%)$ & \\
\hline \multirow{2}{*}{ Open bite } & Present & $29(2.8 \%)$ & $15(51.7 \%)$ & $14(48.3 \%)$ & \multirow{2}{*}{0.86} \\
\hline & Absent & $997(97.2 \%)$ & $499(50.1 \%)$ & $498(49.9 \%)$ & \\
\hline \multirow{2}{*}{ Anterior Crowding } & Present & 524 (51.07\%) & 271 (51.72\%) & $253(48.28 \%)$ & \multirow{2}{*}{0.23} \\
\hline & Absent & $502(48.93 \%)$ & $243(48.4 \%)$ & $259(51.6 \%)$ & \\
\hline \multirow{2}{*}{ Anterior Spacing } & Present & $251(24.46 \%)$ & $131(52.19 \%)$ & $120(47.81 \%)$ & \multirow{2}{*}{0.62} \\
\hline & Absent & 775 (75.54\%) & $383(49.42 \%)$ & $392(50.58 \%)$ & \\
\hline \multirow{2}{*}{ Midline Diastema } & Present & $143(13.9 \%)$ & 69 (48.3\%) & 74 (51.7\%) & \multirow{2}{*}{0.63} \\
\hline & Absent & $883(86.1 \%)$ & $445(50.4 \%)$ & $438(49.6 \%)$ & \\
\hline \multirow{2}{*}{ Anterior Cross bite } & Present & $106(10.3 \%)$ & $50(47.2 \%)$ & $56(52.8 \%)$ & \multirow{2}{*}{0.52} \\
\hline & Absent & $920(89.7 \%)$ & $464(50.4 \%)$ & $456(49.6)$ & \\
\hline \multirow{2}{*}{ Posterior Cross bite } & Present & $70(6.8 \%)$ & $29(41.4 \%)$ & $41(58.6 \%)$ & \multirow{2}{*}{0.13} \\
\hline & Absent & $956(93.2 \%)$ & $485(50.7 \%)$ & $471(49.3 \%)$ & \\
\hline
\end{tabular}


Table 2: Dental Health Component grades of IOTN

\begin{tabular}{|c|c|c|c|c|}
\hline DHC Grade & Need for Treatment & Total & Male & Female \\
\hline Grade $1 \& 2$ & No/ little need of treatment & $602(58.67 \%)$ & $304(59.14 \%)$ & $298(58.20 \%)$ \\
\hline Grade 3 & Borderline & $225(21.93 \%)$ & $120(23.35 \%)$ & $105(20.51 \%)$ \\
\hline Grade 4 \& 5 & Definite treatment need & 199 (19.40\%) & $90(17.51 \%)$ & $109(21.29 \%)$ \\
\hline \multicolumn{2}{|r|}{ Total } & 1026 & 514 & 512 \\
\hline
\end{tabular}

\section{DISCUSSION}

It is the first study of Western region of Nepal to evaluate the prevalence of occlusal traits and correlate them with Dental Health Component of the Index of Orthodontic Treatment Need. It was found that, normal occlusion was 5.8\%, Angle's Class I was 67.9\%, Class II was $19.5 \%$ and Class III was $6.8 \%$. This report is comparable to the previous study of this region by Baral; "1 which showed Angle's Class I in 71\%, Class II in $24.6 \%$ and Class III in 3.9\%. There is also an unison with the study done among eastern population of Nepal by Sharma; ${ }^{7}$ which showed Angle's Class I in 67.5\%, Class II in $28.6 \%$ and Class III in $3.7 \%$. The normal occlusion group in our study was $5.8 \%$ which is relatively less than the report by Shrestha et $a l^{8}$ and Singh et $a l^{10}$ which showed $27 \%$ and $14.4 \%$ respectively. In contrary, Karki et al $^{15}$ showed that Angle's Class III malocclusion was more prevalent than Class II amongst Tibetan ethnic group in the same region; which were $9.40 \%$ and $5.10 \%$ respectively. This could be due to racial variation in occlusal traits. Similarly, increased prevalence of Angle's Class III malocclusion was also seen is Saudi Arabia population (15.5\%). ${ }^{16}$

The present study showed that $39.4 \%$ of the subjects had increased overjet. Similar findings were documented by Shrestha et $a^{8,9}$ and Ciuffolo et al; ${ }^{17}$ which were $43 \%$ and $41 \%$ respectively. In contrary, Karki et al ${ }^{15}$ in Tibetan samples showed increased overjet in only $10.8 \%$.

The present study showed $46.9 \%$ of the samples having overbite; which was slightly more than the samples examined by Sharma ${ }^{13}$ (40\%).
According to the present study, open bite was present in $2.8 \%$ while Karki et $\mathrm{a}^{15}$ and Sharma et $\mathrm{al}^{13}$ showed prevalence of open bite in $10.86 \%$ and $5.1 \%$ respectively.

The present study showed that crowding was more common occlusal trait than spacing which was $51.07 \%$ and $24.46 \%$ respectively; which are similar to Maltese and Brazilian studies. ${ }^{18,19}$ This study showed midline diastema in 13.9\%, anterior cross bite in $10.3 \%$ and posterior cross bite in 6.8\%; while another study on eastern part of Nepal showed midline diastema in 16\%, anterior cross bite in $12.9 \%$ and posterior cross bite in $3.7 \% .{ }^{13}$ The differences could be due to ethnic diversity and study design.

In this study, no statistically significant differences were observed in the distribution of occlusal traits between male and female samples; similar results were exhibited by Baral. ${ }^{11}$

The present study showed various degrees of orthodontic treatment need among western Nepalese samples. The comparison with similar studies within the country and outside is given in Table 3 . The results are comparable to Burden and Holmes ${ }^{22}$ and Hamdan ${ }^{23}$ which showed more number of subjects fall under Grade 1 and 2 (no or little need of treatment) category. In contrary Gyawali20 and Shrestha ${ }^{21}$ showed more number of patients to be on Grade 4 and 5 (Definite need of treatment). This could be because of the fact that, present study was done in general dental patients visiting dental OPD while Gyawali20 and Shrestha ${ }^{21}$ conducted their studies among patients seeking orthodontic treatment.

Table 3: Comparison of IOTN (DHC) data

\begin{tabular}{|c|c|c|c|c|}
\hline Study & $\begin{array}{l}\text { Geographic } \\
\text { Region }\end{array}$ & $\begin{array}{c}\text { Grade } 1 \& 2 \\
\text { (No/ little need of treatment) }\end{array}$ & $\begin{array}{c}\text { Grade } 3 \\
\text { (Borderline need) }\end{array}$ & $\begin{array}{c}\text { Grade } 4 \text { \& } 5 \\
\text { (Definite treatment need) }\end{array}$ \\
\hline Burden, $1994^{22}$ & United Kingdom & $45.99 \%$ & $24.02 \%$ & $29.47 \%$ \\
\hline Hamdan, $2001^{23}$ & Jordan & $50.23 \%$ & $22.18 \%$ & $27.49 \%$ \\
\hline Shrestha, $2012^{21}$ & Central Nepal & $16 \%$ & $19.9 \%$ & $64.1 \%$ \\
\hline Gyawali, $2016^{20}$ & Eastern Nepal & $10.2 \%$ & $24.2 \%$ & $65.7 \%$ \\
\hline Parajuli, 2018 (present study) & Western Nepal & $58.67 \%$ & $21.93 \%$ & $19.40 \%$ \\
\hline
\end{tabular}


The present study comprise of few limitations as it was conducted without ethnic specificity. Multi-centric study with ethnic specificity could provide the national prevalence of occlusal traits with the assessment on need of treatment. This could be implemented in national insurance policy (Social Health Security Program) to cover economic burden for patients with extreme need of orthodontic treatment.

\section{CONCLUSION}

The most prevalent malocclusion traits in patients visiting GMC-College of Dental Surgery is Angle's Class
I followed by anterior crowding. Almost $20 \%$ of the patients are in definite or extreme need of orthodontic treatment in Pokhara.

\section{Acknowledgement}

Sincere thanks to Prof Ishwari Sharma Paudel, Dept. of Community Medicine and Dr. Nuwadatta Subedi, Dept of Forensic Medicine, Gandaki Medical College for helping in statistical analysis.

\section{REFERENCES}

1. Proffit WR, Fields HW Jr, Moray LJ. Prevalence of malocclusion and orthodontic treatment need in the United States: estimates from the NHANES III survey. Int J Adult Orthod Orthognath Surg. 1998; 13(2):97-106.

2. Ghabrial E, Wiltshire WA, Zietsman ST, Viljoen E. The epidemiology of malocclusion in Zambian urban school children. J South African Dent Asso. 1998; 53(8):405-8.

3. Thilander B, Myrberg N. The prevalence of malocclusion in Swedish school children. Scandinavian J Dent Res. 1973; 81 (1):12-21.

4. Profitt WR. Malocclusion and Dentofacial Deformity in Contemporary Society. Contemporary Orthodontics, 3rd ed. Missouri, Mosby; 2000:2-21.

5. Klages U, Bruckner A, Zentner A. Dental aesthetics, self-awareness, and oral health-related quality of life in young adults. Eur J Orthod. 2004; 26(5):507-14.

6. Evans R, Shaw W. Preliminary evaluation of an illustrated scale for rating dental attractiveness. Eur J Orthod. 1987; 9(4):314-8.

7. Sharma JN. Epidemiology of malocclusions and assessment of orthodontic treatment need for the population of eastern Nepal. World J Orthod. 2009; 10(4):311-6.

8. Shrestha BK, Yadav R, Basel P. Prevalence of malocclusion among high school students in Kathmandu Valley. Orthod J Nepal. 2012;2(1):1-5.

9. Shrestha BK, Yadav R, Gyawali R, Gupta S. Prevalence of malocclusion among medical students in Institute of Medicine, Nepal: A preliminary report. Orthod J Nep. 2011;1:24-7.

10. Singh VP, Sharma A. Epidemiology of malocclusion and assessment of Orthodontic Treatment Need for Nepalese children. International Scholarly Research Notices. 2014; Article ID 768357, 4 pages, 2014. https://doi.org/10.1155/2014/768357.

11. Baral P. Prevalence of malocclusion in Western Nepal. Orthod J Nep. 2015;5(2):6-8.

12. Baral P. Prevalence of malocclusion in permanent dentition in Aryan and Mongoloid races of Nepal: A comparative study. Pak Oral J.2013:52:57-9.

13. Sharma JN. Pattern of distribution of malocclusions in patients seeking orthodontic treatment at BPKIHS from Sunsari District of Nepal. Health Renaissance. 2010;8(2):93-6.

14. WHO - Oral Health survey, Basic. methods. 4th ed. New Delhi; AlTBS Publishers and distributors; 1999.

15. Karki S, Parajuli U, Kunwar N, Namgyal K, Wangdu K. Distribution of malocclusion and occlusal traits among Tibetan adolescents residing in Nepal. Orthod J Nep. 2014;4(2):28-31.

16. Gudipaneni RK, Aldahmeshi RF, Patil SR, Alam MK. The prevalence of malocclusion and the need for orthodontic treatment among adolescents in the northern border region of Saudi Arabia: an epidemiological study. BMC Oral Health. $2018 ; 18: 16$.

17. Ciuffolo F, Manzoli L, D'Attilio M, Tecco S, Muratore F, Festa F, Romano F. Prevalence and distribution by gender of occlusal characteristics in a sample of Italian secondary school students: a cross sectional study. Eur J Orthod. 2005; 27: 601-6.

18. Camilleri S, Mulligan K. The prevalence of malocclusion in Maltese schoolchildren as measured by the index of orthodontic treatment need. Malta Med J. 2007;19(1): 19-24.

19. Brito DI, Dias PF, and Gleiser R. Prevalence of malocclusion in children aged 9-12 years old in the city of nova friburgo, rio de Janeiro State, Brazil. Revista Dental Press de Ortodontiae Orthopedia Facial. 2009;14(6): 118-24.

20. Gyawai R, Pokharel PR, Giri J, Shrestha GK, Bhattarai B. Index of orthodontic treatment need of patients undergoing orthodontic treatment at BPKIHS, Dharan. Orthod J Nep. 2016 Jun; 6(1):23-6.

21. Shrestha S, Shrestha RM. Index of Orthodontic Treatment Need in referred Nepalese population. Orthod J Nep. $2013 ; 2$ (1):9-15.

22. Burden DJ, Holmes A. The need for orthodontic treatment in the child population of the United Kingdom. Eur J Orthod.1994; 16(5): 395-9.

23. Hamdan AM. Orthodontic treatment need in Jordanian school children. Community Dental Health. 2001;18(3):177-80. 